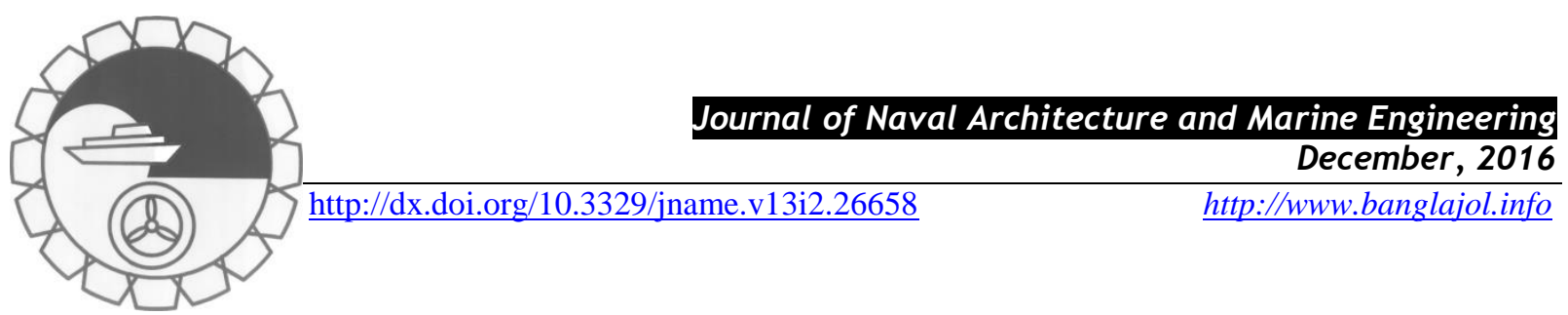

\title{
STRESS DISTRIBUTION IN CNT-ALUMINUM MATRIX COMPOSITE BY CHANGING DISTANCES BETWEEN CNT BUNDLES
}

\author{
H. T. Chowdhury ${ }^{1}$, A. K. M. Masud ${ }^{2}$ \\ ${ }^{1}$ Department of Industrial \& Production Engineering, Dhaka University of Engineering \& Technology, Gazipur, Bangladesh, \\ Email: tabassum.u@ duet.ac.bd \\ ${ }^{2}$ Department of Industrial Engineering, Faculty of Engineering, University of Jeddah, Jeddah, KSA, Email: \\ masaod@uj.edu.sa
}

\begin{abstract}
:
Carbon Nanotubes (CNTs) are identified as exceptional in terms of mechanical, electrical, magnetic and optical properties. CNT based composites are also playing a vital role in several fields of science. In this research, four bundles of CNTs with square Representative Volume Element (RVE) are used and ANSYS Multiphysics 11.0 software is used for simulation purpose. In this study, stress distribution of CNT based Aluminum composite is noticed by changing distances of CNT bundles. Stress distribution and transverse Young's Modulus are investigated by changing different parameters. From this study it can be known how CNT bundles can be formed together to increase or decrease stress. The brief result is that, if the distance of CNT center from reference point is increased then the stress is decreased.
\end{abstract}

Keywords: Carbon Nanotubes (CNTs), RVE, Stress distribution, Young's Modulus, ANSYS Multiphysics 11.0.

$\begin{array}{clcl}\text { NOMENCLATURE } & & \\ (n, m) & \text { Chiral indices } & E_{z} & \begin{array}{l}\text { Effective longitudinal Young's Modulus } \\ \text { of CNT based composite }\end{array} \\ L & \text { Length of long CNT bundle based composite } & E^{t} & \text { Young's Modulus of CNT } \\ a & \text { Width of RVE } & E^{m} & \text { Young's Modulus of matrix } \\ V^{t} & \text { CNT volume fraction } & \pi & \text { A constant (3.14) } \\ r_{o} & \text { CNT outer radius } & & \\ r_{i} & \text { CNT inner radius } & & \end{array}$

\section{Introduction}

Carbon nanotubes are composed of carbon atoms and they have diameters as $1 \mathrm{~nm}$ and lengths up to several centimeters ("What are Carbon Nanotubes", n.d.). They are strong and flexible ("What are Carbon Nanotubes", n.d.). Multi-walled carbon nanotubes (MWNT) are those when carbon nanotubes are comprised of multiple concentric cylinders of carbon atoms and single cylinder carbon nanotubes are called single-walled carbon nanotubes (SWNT) ("What are Carbon Nanotubes", n.d.). A graphite sheet can be rolled up to make a tube of single wall carbon nanotube. Carbon nanotubes can be of three different types like armchair, zig-zag and chiral depending on the way how the graphene sheet is rolled according to the chiral angle ("Nanotubes and Buckyballs", 2015, April 20) which is the wrapping angle and can be represented by a pair of indices called chiral indices $(\mathrm{n}, \mathrm{m})$ where integers $\mathrm{n}$ and $\mathrm{m}$ denote the number of unit vectors along two directions in honeycomb crystal lattice of graphene ("Carbon nanotube", 2016, June 16).

CNTs have extremely high stiffness, strength and resilience (Peebles, 1995). Tests have the evidence that the micro-hardness measured on the Vickers scale increases with the increase of nanotube content in the Aluminum matrix (Srivastava et al, 2008). Carbon nanotube reinforced Aluminum composites have slight increase in electrical resistivity (Shadakshari et al, 2012). A reduction in the ductility of the composite for the addition of CNT is observed (Shadakshari et al, 2012). 
In aerospace structure, Aluminum is the most suitable material to use (Udupa et al, 2014). If CNT is used as the reinforcement material in Aluminum matrix, this will make a composite of greater strength, improved stiffness, reduced density, improved abrasion and wear resistance, improved damping capabilities and many more (Udupa et al, 2014).

Researchers have done many experiments and simulations to investigate the properties of CNT reinforced composites. Some researchers showed that an addition of $1 \%$ CNT by weight in a matrix, result in an increase in elastic stiffness of the composite (Chen et al, 2004). From the other studies, it has been found that CNT has Young's modulus in the range of tera pascal ("Carbon nanotube", 2016, June 16). Elastic properties and load carrying capacities of CNTs have been demonstrated in several research works.

Reinforcement of carbon nanotube has been employed successfully for over many years to improve mechanical properties of products. Combining high modulus, high strength carbon nanotube with a polymetric matrix produces a composite material with higher stiffness and strength and lower thermal expansion coefficient (Thostenson et al, 2001). With the technological advancement, the search for lightest and as well as strongest material is increasing day by day and CNT reinforced Aluminum composite is one of the potential candidates in this case. In this research, CNT reinforced Aluminum composite is considered to investigate different relationships with stress.

In this paper, Aluminum is used as matrix and carbon nanotube is the reinforcing material. Four individual square RVE models are united together for the final model and for the convenience to simulate; quarter 2-D model of it is used. ANSYS Multiphysics 11.0 software is used to simulate the model.

In the simulation, $1 \mathrm{~nm}$ axial displacement is given to the model and the result is; with the increase of RVE width (when chiral index and thickness is same and distance of CNT center from reference point increases) stress decreases and Young's modulus decreases.

\section{Model Formulation}

The distribution and orientation of CNTs in the matrix can be uniform and unidirectional or random. These factors make the simulations of CNT based composites extremely difficult (Masud et al, 2009). So the concept of RVE which is the smallest volume and a measurement over this yields a value representing the whole ("Representative Elementary Volume", 2016, May 10). There are cylindrical RVE, square RVE and hexagonal RVE (Joshi et al, 2010).

In the production processes, it is difficult to get isolated CNT and CNTs have a propensity to aggregate to bundle or wrap together due to high surface energy and surface area and they are used in composite in this bundled form (Islam et al, 2011).

CNT is embedded inside the RVE for short CNT based composite and throughout the length in one of the corners in case of long bundle based CNT (Islam et al, 2011).

In this research following assumptions are considered,

- The surface is plain

- Van der Waals force is ignored

- Isotropic material is chosen for simulation

- Theoretical rule of mixture for composites is used for obtaining Young's Modulus.

\subsection{Square RVE and long bundle CNT based composite}

RVE used here is square and for long CNT bundle based composite it has length L and width a as shown in Figure 1. 


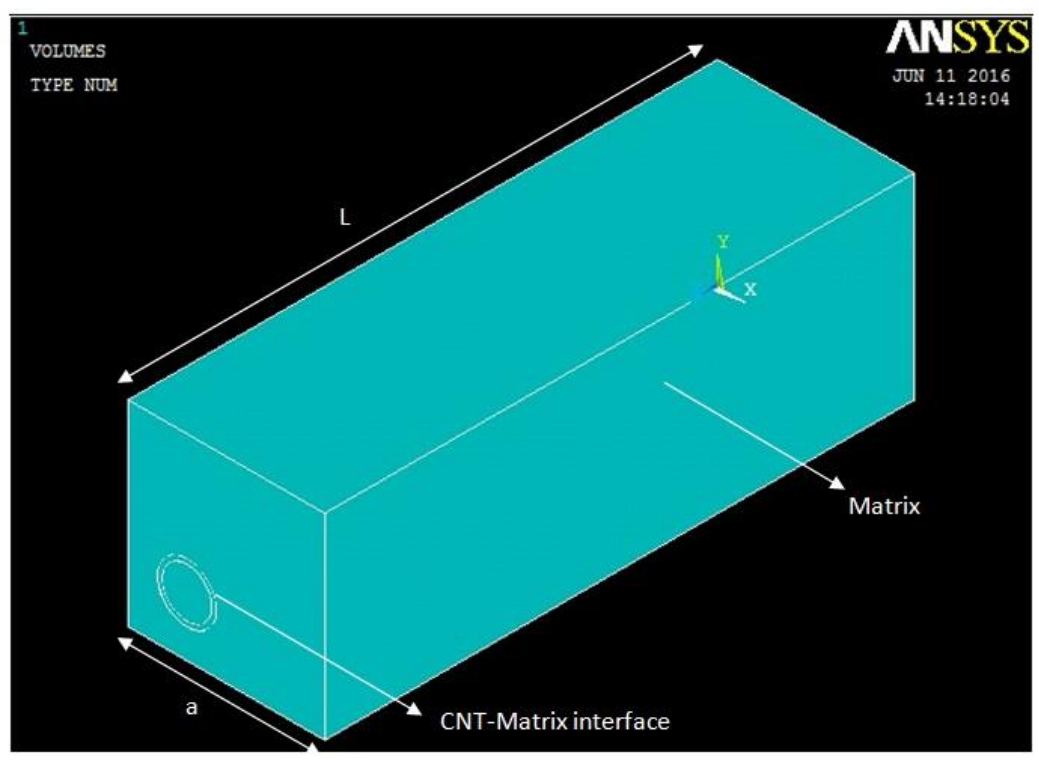

Figure 1: RVE for long CNT bundle based composite

While modeling by the software ANSYS, Plane82 has been considered. In Plane82, the 8-node element is defined by eight nodes having two degrees of freedom at each node ("4.82 PLANE82 2-D 8-Node Structural Solid", n.d.). For armchair type carbon nanotubes, integers $n$ and $m$ of chiral indices are same which means $n=m$ and the chiral indices would be then $(n, n)$.

In this model, two chiral indices are considered: $(50,50)$ and $(73,73)$. Thickness of CNT and distances between CNT bundles are varied to investigate the effect on stress.

In the united four RVE model, the intersection of horizontal and vertical line is taken as reference point (figure 2). To see the effect on stress, the distances between this reference point and center of CNT is varied.

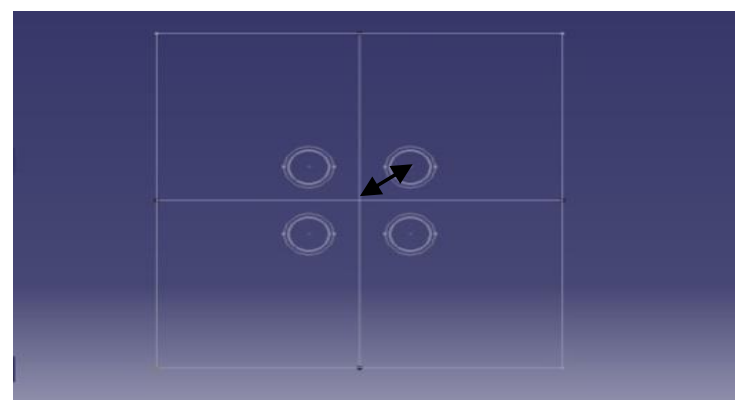

Figure 2: Reference point is the intersection of horizontal and vertical line

For chiral index $(50,50)$, when thickness is $0.34 \mathrm{~nm}$ and RVE width is $30 \mathrm{~nm} ; 21.21 \mathrm{~nm}$ distance from the reference point to the center of CNT is considered. Then RVE width is changed to 20nm and distance is changed to $11.31 \mathrm{~nm}$ keeping thickness same at previous $0.34 \mathrm{~nm}$. Again, thickness is changed to $0.4 \mathrm{~nm}$ keeping RVE width and distance from reference point same to previous.

For chiral index $(73,73)$; when thickness is $0.34 \mathrm{~nm}$ and RVE width is $30 \mathrm{~nm}$ then distance from reference point is considered $21.21 \mathrm{~nm}$. Another case by changing RVE width to $20 \mathrm{~nm}$ and distance from reference point is $14.14 \mathrm{~nm}$ and $9.89 \mathrm{~nm}$.

Stress distribution and Young Modulus is determined for all these cases.

\subsection{Calculation of volume fraction and radius of CNT}

The CNT is throughout the RVE in long CNT based composite. For square RVE, the volume fraction is defined by the following equation (Islam et al, 2013): 
$V^{t}=\frac{\pi\left(r_{0}^{2}-r_{i}^{2}\right)}{a^{2}-\pi r_{i}^{2}}$

Here,

$V^{t}$ is CNT volume fraction, $r_{o}$ is CNT outer radius, $r_{i}$ is CNT inner radius and $a$ is width of RVE

For calculating outer radius $r_{o}$ and inner radius $r_{i}$ of CNT, the equation is (Islam et al, 2013):

$r_{\text {mean }}=\frac{\sqrt{3} \times 0.144 \times \sqrt{\left(n^{2}+m^{2}+m n\right)}}{2 \pi}$

Where, $(n, m)$ is chiral index.

CNT thickness is $r_{0}-r_{i}$

If $r_{0}-r_{i}$ is $0.34, r_{0}=r_{\text {mean }}+0.17$ and $r_{i}=r_{\text {mean }}-0.17$

If $r_{0}-r_{i}$ is $0.4, r_{0}=r_{\text {mean }}+0.2$ and $r_{i}=r_{\text {mean }}-0.2$

\subsection{Young's modulus for composites}

The rule of mixtures can be applied to verify the numerical results for the effective Young's modulus in the CNT axial direction.

The effective longitudinal Young's Modulus $E_{z}$ for long CNT based composite in the axial direction is (Islam et al, 2011),

$E_{z}=E^{t} V^{t}+E^{m}\left(1-V^{t}\right)$

Where,

$E^{t}$ is Young's Modulus of CNT, $E^{m}$ is Young's Modulus of matrix and $V^{t}$ is volume fraction of CNT

And effective transverse Young’s Modulus of composite (Islam et al, 2011),

$\frac{1}{E_{z}}=\frac{V^{t}}{E^{t}}+\frac{\left(1-V^{t}\right)}{E^{m}}$

\section{Results and Discussion}

Different parameters are changed to investigate the effect on stress distribution. Such as,

i. Chiral index and thickness are same and distance of CNT center from reference point is changed

ii. Chiral index, distance of CNT center from reference point and RVE width are same and thickness is changed iii. Chiral index, RVE width and thickness are same and distance of CNT center from reference point is changed iv. Thickness of CNT, distance of CNT center from reference point and RVE width are same and chiral index is changed

These parameters are selected as they are important parameters for carbon nanotube and it is observed here how stress is related with them. The values associated with them are taken randomly.

CNT radius for different thickness and chiral index are showed in Table 1.

Table 1: Determination of CNT radius

\begin{tabular}{|c|c|c|c|c|}
\hline $\begin{array}{c}\text { Chiral } \\
\text { index }\end{array}$ & $\begin{array}{c}\text { CNT } \\
\text { thickness } \\
(\mathrm{nm})\end{array}$ & $\begin{array}{c}\text { CNT mean } \\
\text { radius } \\
\left(r_{\text {mean }} \mathrm{nm}\right)\end{array}$ & $\begin{array}{c}\text { CNT outer } \\
\text { radius } \\
\left(r_{o} \mathrm{~nm}\right)\end{array}$ & $\begin{array}{c}\text { CNT inner } \\
\text { radius } \\
\left(r_{i} \mathrm{~nm}\right)\end{array}$ \\
\hline$(50,50)$ & 0.34 & 3.44 & 3.61 & 3.27 \\
\hline$(50,50)$ & 0.4 & 3.44 & 3.64 & 3.24 \\
\hline$(73,73)$ & 0.34 & 5.02 & 5.19 & 4.85 \\
\hline
\end{tabular}


Volume fraction is the fraction of the total volume occupied by a component in composite materials ("What is Volume Fraction?", n.d.). A study showed that incorporation of 5\% by volume of nanotubes in aluminum increased the tensile strength by a factor of 2 compared to pure aluminum subjected to the same processing (Poole \& Owens, 2003) and in this research simulation results of tensile stress are also showed similar value. By this way the model was first validated. In Table 2, volume fraction of CNT is determined.

Table 2: Determination of volume fraction of CNT for different chiral index, thickness and RVE width

\begin{tabular}{|c|c|c|c|}
\hline $\begin{array}{c}\text { Chiral } \\
\text { index }\end{array}$ & $\begin{array}{c}\text { CNT thickness } \\
(\mathrm{nm})\end{array}$ & $\begin{array}{c}\text { RVE width } \\
\left({ }^{\prime} a \text { ' } \mathrm{nm}\right)\end{array}$ & $\begin{array}{c}\text { Volume fraction } \\
\left(V^{t}\right)\end{array}$ \\
\hline \multirow{3}{*}{$(50,50)$} & 0.34 & 30 & $0.85 \%$ \\
\cline { 2 - 4 } & 0.4 & 20 & $2 \%$ \\
\cline { 2 - 4 } & 0.34 & 20 & $2.4 \%$ \\
\cline { 2 - 4 }$(73,73)$ & \multirow{2}{*}{0.30} & $1.3 \%$ \\
\hline
\end{tabular}

\subsection{Effect on stress of nanocomposite by changing different parameters}

Six cases are considered here. To investigate the effect on stress, $1 \mathrm{~nm}$ axial displacement is given to the model. Case 1: Chiral index $(50,50)$; thickness of CNT $0.34 \mathrm{~nm}$; RVE width 30nm; distance of CNT center from reference point $21.21 \mathrm{~nm}$. Here maximum stress is $0.276 \mathrm{e} 10 \mathrm{~Pa}$.

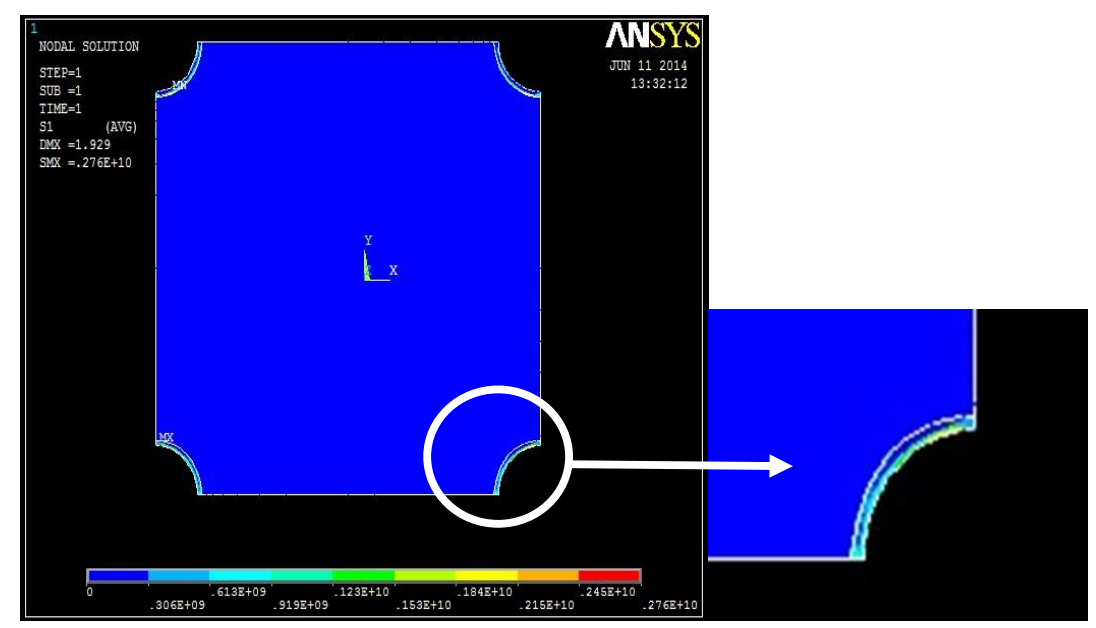

Figure 3: Stress distribution for case 1

Case 2: Chiral index (50,50); thickness of CNT 0.34nm; RVE width 20nm; distance of CNT center from reference point $11.31 \mathrm{~nm}$. Here maximum stress is $0.102 \mathrm{e} 12 \mathrm{~Pa}$.

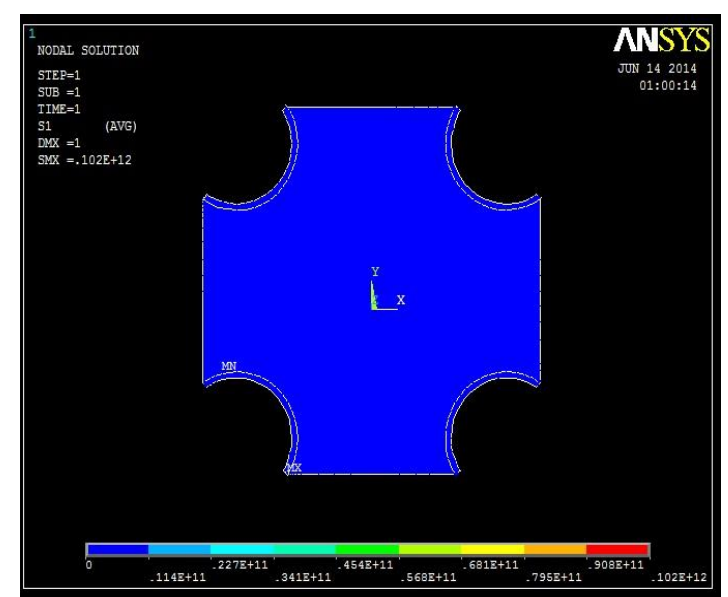

Figure 4: Stress distribution for case 2

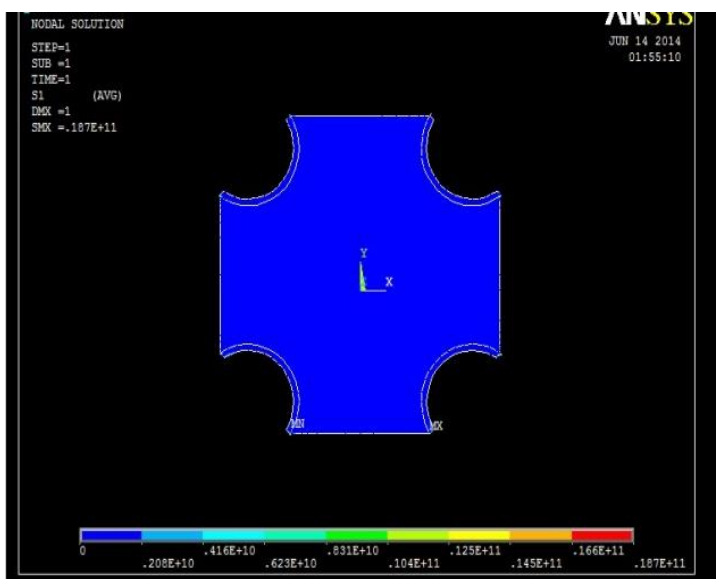

Figure 5: Stress distribution for case 3 
Case 3: Chiral index $(50,50)$; thickness of CNT $0.4 \mathrm{~nm}$; RVE width 20nm; distance of CNT center from reference point $11.31 \mathrm{~nm}$. Here maximum stress is $0.187 \mathrm{e} 11 \mathrm{~Pa}$.

Case 4: Chiral index (73,73); thickness of CNT 0.34nm; RVE width 30nm; distance of CNT center from reference point $21.21 \mathrm{~nm}$. Here maximum stress is $0.268 \mathrm{e} 10 \mathrm{~Pa}$.

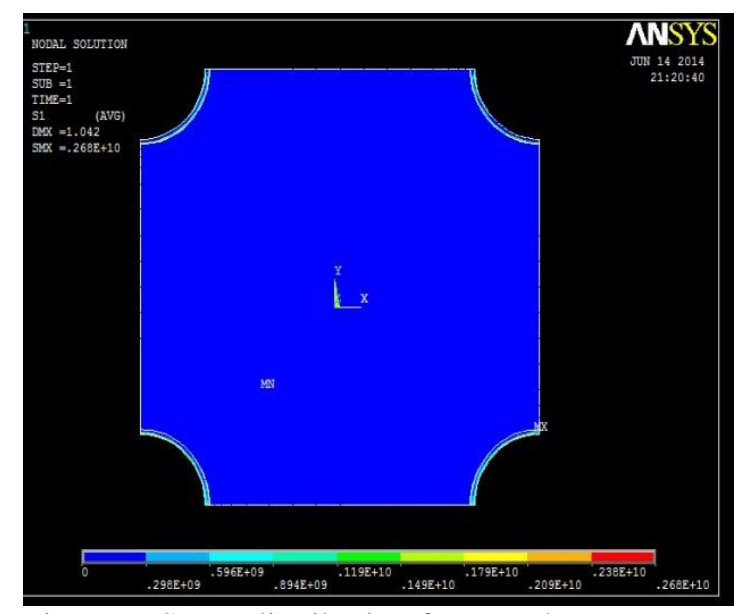

Figure 6: Stress distribution for case 4

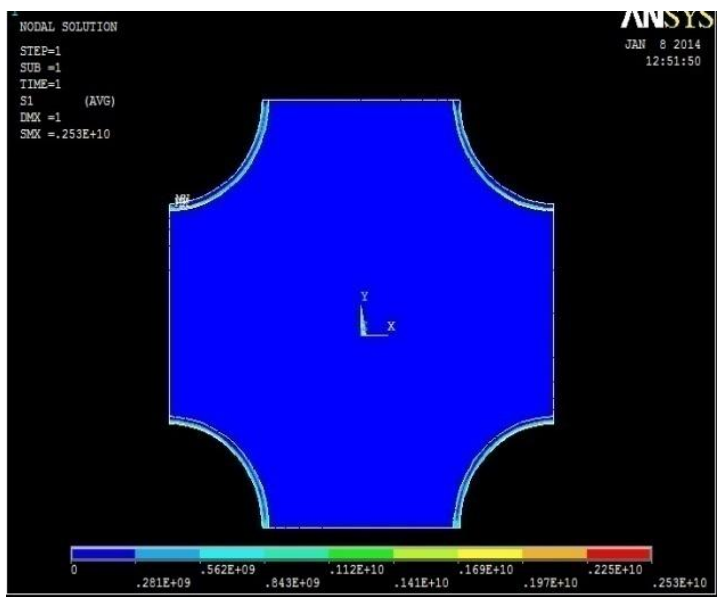

Figure 7: Stress distribution for case 5

Case 5: Chiral index (73,73); thickness of CNT 0.34nm; RVE width 20nm; distance of CNT center from reference point is $14.14 \mathrm{~nm}$. Here maximum stress is $0.253 \mathrm{e} 10 \mathrm{~Pa}$.

Case 6: Chiral index (73,73); thickness of CNT 0.34nm; RVE width 20nm; distance of CNT center from reference point $9.89 \mathrm{~nm}$. Here maximum stress is $0.159 \mathrm{e} 11 \mathrm{~Pa}$.

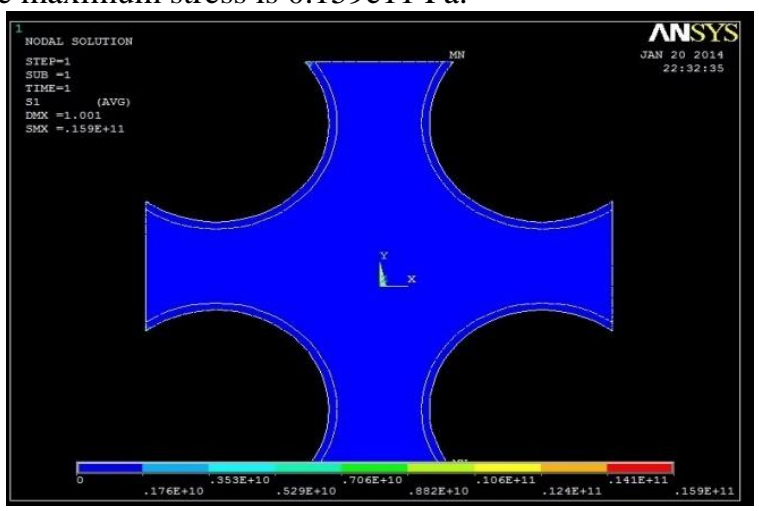

Figure 8: Stress distribution for case 6

Table 3 shows the relation between stress and RVE width of CNT. For chiral index $(50,50)$ and thickness of CNT 0.34nm; when RVE width is $20 \mathrm{~nm}$ (distance from reference point $11.31 \mathrm{~nm}$ ) stress is $1.02 \times 10^{11} \mathrm{~Pa}$ and when RVE width is $30 \mathrm{~nm}$ (distance from reference point $21.21 \mathrm{~nm}$ ) stress is $0.276 \times 10^{10} \mathrm{~Pa}$.

Table 3: Relation between stress and RVE width

\begin{tabular}{|l|l|}
\hline RVE width & Stress $(\mathrm{Pa})$ \\
\hline $\begin{array}{l}\text { RVE width 20nm (distance from } \\
\text { reference point } 11.31 \mathrm{~nm})\end{array}$ & $1.02 \times 10^{11}$ \\
\hline $\begin{array}{l}\text { RVE width 30nm (distance from } \\
\text { reference point } 21.21 \mathrm{~nm})\end{array}$ & $0.276 \times 10^{10}$ \\
\hline
\end{tabular}

Table 4 denotes that, when distance of CNT center from reference point, chiral index and RVE width are same; stress decreases with the increase of CNT thickness. 
Table 4: Relation between stress and thickness of CNT

\begin{tabular}{|c|c|}
\hline $\begin{array}{c}\text { Thickness of CNT (nm) } \\
\text { (distance of CNT center from reference } \\
\text { point 11.31 nm, chiral index }(50,50) \\
\text { and RVE width 20nm) }\end{array}$ & Stress $(\mathrm{Pa})$ \\
\hline 0.34 & $1.02 \times 10^{11}$ \\
\hline 0.4 & $1.87 \times 10^{10}$ \\
\hline
\end{tabular}

Table 5 shows when thickness of CNT, chiral index and RVE width is same; stress decreases with the increase of distance of CNT center from reference point.

Table 5: Relation between stress and distance of CNT center from reference point

\begin{tabular}{|c|c|}
\hline $\begin{array}{l}\text { Distance of CNT center from reference } \\
\text { point (nm) } \\
\text { (chiral index }(73,73) \text {, thickness of } \\
\text { CNT } 0.34 \mathrm{~nm}, \text { RVE width } 20 \mathrm{~nm} \text { ) }\end{array}$ & Stress $(\mathrm{Pa})$ \\
\hline 9.89 & $1.59 \times 10^{10}$ \\
\hline 14.14 & $2.53 \times 10^{09}$ \\
\hline
\end{tabular}

Table 6 tells that, when thickness of CNT, RVE width and distance of CNT center from reference point are same; stress decreases with the increase of chiral index.

Table 6: Relation between stress and chiral index of CNT

\begin{tabular}{|c|c|}
\hline $\begin{array}{c}\text { Chiral Index } \\
\text { (thickness of CNT 0.34nm; RVE width } \\
\text { 30nm; distance of CNT center from } \\
\text { reference point 21.21 nm) }\end{array}$ & Stress (Pa) \\
\hline$(50,50)$ & $2.76 \times 10^{09}$ \\
\hline$(73,73)$ & $2.68 \times 10^{09}$ \\
\hline
\end{tabular}

\subsection{Effect on Young's modulus by changing distances between reference point and center of} CNT

Aluminum matrix has Young modulus of $69 \mathrm{GPa}$ and Single wall Carbon nanotube has Young modulus of 1000 GPa or 1Tpa. Rule of mixtures is applied here for Effective Young's Modulus.

In Table 7, we can see the changes of Effective Young's modulus for different cases considered here.

Table 7: Changes of Effective Young's Modulus for different cases

\begin{tabular}{|c|c|}
\hline & Effective Young's Modulus(Pa) \\
\hline Case 1 & $7.69 \times 10^{10}$ \\
\hline Case 2 & $8.76 \times 10^{10}$ \\
\hline Case 3 & $9.13 \times 10^{10}$ \\
\hline Case 4 & $8.11 \times 10^{10}$ \\
\hline Case 5 & $9.97 \times 10^{10}$ \\
\hline
\end{tabular}

Table 8 shows that, when chiral index and thickness of CNT are same; effective Young's Modulus decrease with the increase of RVE width.

Table 8: Change of Effective Young's modulus with RVE width

\begin{tabular}{|c|c|}
\hline $\begin{array}{c}\text { RVE width (nm) } \\
\text { (chiral index (50,50) and thickness of } \\
\text { CNT is 0.34nm) }\end{array}$ & Effective Young's Modulus (Pa) \\
\hline 20 & $8.76 \times 10^{10}$ \\
\hline 30 & $7.69 \times 10^{10}$ \\
\hline
\end{tabular}


Table 9 denotes that, when chiral index and RVE width are same; effective Young's Modulus increases with the increase of thickness of CNT.

Table 9: Change of effective Young's modulus with CNT thickness

\begin{tabular}{|c|c|}
\hline $\begin{array}{c}\text { Thickness of CNT (nm) } \\
\text { (chiral index }(50,50) \text { and RVE width } \\
20 \mathrm{~nm})\end{array}$ & Effective Young's Modulus (Pa) \\
\hline 0.34 & $8.76 \times 10^{10}$ \\
\hline 0.4 & $9.13 \times 10^{10}$ \\
\hline
\end{tabular}

From Table 10 we can see that, when chiral index, thickness of CNT and RVE width are same; effective Young's Modulus is same with the increase of distance of CNT center from reference.

Table 10: Change of effective Young's modulus with distance of CNT center from reference point

\begin{tabular}{|c|c|}
\hline $\begin{array}{l}\text { Distance of CNT center from reference } \\
\text { point }(\mathrm{nm}) \\
\text { (chiral index }(73,73) \text {, thickness of } \\
\text { CNT } 0.34 \mathrm{~nm}, \text { RVE width } 20 \mathrm{~nm} \text { ) }\end{array}$ & Effective Young's Modulus (Pa) \\
\hline 9.89 & $9.97 \times 10^{10}$ \\
\hline 14.14 & $9.97 \times 10^{10}$ \\
\hline
\end{tabular}

Table 11 denotes that when CNT thickness and RVE width are same; effective Young's Modulus increases for the increase in chiral index.

Table 11: Change of Effective Young's Modulus with chiral index

\begin{tabular}{|c|c|}
\hline Chiral Index & Effective Young's Modulus (Pa) \\
\hline$(50,50)$ & $7.69 \times 10^{10}$ \\
\hline$(73,73)$ & $8.11 \times 10^{10}$ \\
\hline
\end{tabular}

If chiral index and thickness are fixed then stress decreases with the increase of RVE width with increasing distance of CNT center from reference point. It is showed that agglomerate stress decreases with the increase of nano powder diameter (Henry et al, 2013). Here also this type of phenomena has been observed. When CNTs are agglomerated closely, they have higher stress.

Theoretically for thin walled cylinder, axial stress and thickness are inversely proportional. Here, if we consider single wall carbon nanotube as a thin walled cylinder, when other parameters are fixed, the stress is inversely proportional to thickness. And all the other observations indicate that closely agglomerated CNTs have higher stress.

When chiral index and thickness of CNT are same; effective Young's Modulus decrease with the increase of RVE width as then volume fraction of CNT decreases with the increase of RVE width. When chiral index and RVE width are same; effective Young's Modulus increases with the increase of thickness of CNT as then volume fraction increases when thickness increases. When chiral index, thickness of CNT and RVE width are same; effective Young's Modulus is same with the increase of distance of CNT center from reference point as here volume fraction of CNT is same. When CNT thickness and RVE width are same; effective Young's Modulus increases for the increase in chiral index as volume fraction increases. These results are useful to select parameter for CNT-Aluminum composite.

\section{Conclusion}

In this paper, the effect on stress of CNT reinforced Aluminum composite by changing distances between bundles is investigated. The simulation results say that:

- Stress decreases and Young's modulus decreases with the increase of RVE width when chiral index and thickness is same and distance of CNT center from reference point increases

- Stress decreases and Young's modulus increases with the increase of thickness of CNT when chiral index, distance of CNT center from reference point and RVE width is same 
- $\quad$ Stress decreases and Young's modulus almost same with the increase of distance of CNT center from reference point when chiral index, RVE width and thickness is same

- Stress decreases and Young's modulus increases with the increase of chiral index when thickness of CNT, distance of CNT center from reference point and RVE width is same

In brief it is found that if the distance of CNT center from reference point is increased then the stress is decreased.

\section{References}

4.82 PLANE82 2-D 8-Node Structural Solid, $\quad$ (n.d.), $\quad$ Retrieved from http://www.ansys.stuba.sk/html/elem_55/chapter4/ES4-82.htm

Carbon nanotube, (2016, June 16), Retrieved from https://en.wikipedia.org/wiki/Carbon_nanotube

Chen, X.L. and Liu, Y.J. (2004): Square Representative Volume Elements for Evaluating the Effective Material Properties of Carbon Nanotube-Based Composites, Computational Materials Science, Vol. 29, Issue 1, pp. 1-11. http://dx.doi.org/10.1016/s0927-0256(03)00090-9

Henry, F., Marchal, P., Bouillard, J., Vignes, A., Dufaud, O. and Perrin, L. (2013): The Effect of Agglomeration on the Emission of Particles from Nanopowders Flow, Chemical Engineering Transactions, Vol. 31, pp. 811-816. 10.3303/CET1331136

Islam, M. S. and Szpunar, J. (2013): Effects of Orientation of Carbon Nanotubes on CNT Bundle Based Silk Composite Using Finite Element Method, Modeling and Numerical Simulation of Material Science, Vol. 3, pp. 33-38. http://dx.doi.org/10.4236/mnsms.2013.31005

Islam, M. S., Riktan, F. O., Chowdhury, S. C., Chowdhury, M. M. R. and Ahmed, S. (2011): Evaluation of Tensile Modulus of Carbon Nanotube Bundle Based Composite with Interface Using Finite Element Method, Proceedings of the 2011 COMSOL Conference in Bangalore

Joshi, U. A., Joshi, P., Harsha, S. P. and Sharma, S. C. (2010): Evaluation of the Mechanical Properties of Carbon Nanotube Based Composites by Finite Element Analysis, International Journal of Engineering Science and Technology, Vol. 2, No. 5, pp. 1098-1107.

Masud, A.K.M., Tahreen, N. and Abedin, F. (2009): Effects of Interphase and Matrix Properties on Effective Tensile Elastic Modulus of Carbon Nanotube-Based Composite, Journal of Mechanical Engineering, Vol. 40, Issue 1, pp. 29-38. http://dx.doi.org/10.3329/jme.v40i1.3471

Nanotubes and Buckyballs, (2015, April 20), Retrieved from http://www.nanotech-now.com/nanotubebuckyball-sites.htm

Poole, C. P. and Owens, F. J. (2003): Introduction to Nanotechnology, Hoboken, New Jersey: John Wiley \& Sons.

Peebles, L. H. (1995): Carbon Fibers: Formation, Structure and Properties, Boca Raton, FL: CRC Press.

Representative Elementary Volume, (2016, May 10), Retrieved from https://en.wikipedia.org/wiki/Representative elementary volume

Shadakshari, R., Mahesha K., and Niranjan H. B. (2012): Carbon Nanotube Reinforced Aluminium Matrix Composites - A Review, International Journal of Innovative Research in Science, Engineering and Technology, Vol. 1, Issue 2, pp. 206-213.

Srivastava, A. K., Xu, C. L., Wei, B. Q., Kishore, R. and Sood, K. N. (2008): Microstructural Features and Mechanical Properties of Carbon Nanotubes Reinforced Aluminum-Based Metal Matrix Composites, Indian Journal of Engineering \& Materials Sciences, Vol. 15, pp. 247-255.

Thostenson, E. T., Ren, Z. and Chou, T. (2001): Advances in the Science and Technology of Carbon Nanotubes and Their Composites: A Review, Composites Science and Technology, Vol. 61, Issue 13, pp. 1899-1912. http://dx.doi.org/10.1016/s0266-3538(01)00094-x

Udupa, G., Rao, S. S. and Gangadharan, K. V. (2014): A Review of Carbon Nanotube Reinforced Aluminium Composite and Functionally Graded Composites as a Future Material for Aerospace, International Journal of Modern Engineering Research, Vol. 4, Issue 7, pp. 13-22.

What are Carbon Nanotubes?, (n.d.), Retrieved from http://www.understandingnano.com/what-are-carbonnanotubes.html

What is Volume Fraction?, (n.d.), Retrieved from http://thesciencedictionary.org/volume-fraction/ 